\title{
Risk management of knowledge loss in nuclear industry organisations
}

\author{
James Edwin Boyles* \\ 443 Bald Eagle Circle \\ Chattanooga, TN 37419, USA \\ E-mail: jeboyles@comcast.net \\ *Corresponding author

\section{Frank Kirschnick} \\ Cassantec Ltd, Technoparkstrasse 1 \\ CH-8005 Zurich, Switzerland \\ E-mail: frank.kirschnick@cassanteccom
}

\author{
A. Kosilov and Y. Yanev \\ Nuclear Knowledge Management Unit \\ International Atomic Energy Agency \\ P.O. Box 100A-1400 Vienna, Austria \\ E-mail: a.kosilov@iaea.org \\ E-mail: y.yanev@iaea.org
}

\section{T. Mazour}

NENP - Nuclear Power Engineering Section

International Atomic Energy Agency

P.O. Box 100A-1400 Vienna, Austria

E-mail: t.mazour@iaea.org

\begin{abstract}
Maintaining nuclear competencies in the nuclear industry and nuclear regulatory authorities will be one of the most critical challenges in the near future. As many nuclear experts around the world are approaching retirement, the potential exists for the loss of a substantial amount of critical nuclear knowledge and corporate memory. The loss of such employees, many of whom literally designed, constructed and now operate existing nuclear power plants, poses a clear internal threat to the continued operations of these facilities. In addition, the loss of this knowledge and expertise could impact future plans for the construction of new, advanced nuclear units. This paper provides practical guidance on knowledge loss risk management. The guidance is based upon the actual experiences of IAEA member states' operating organisations and is intended to increase awareness of the need to develop an integrated and strategic approach to capture critical knowledge before it is lost. The specific objectives of the paper are to enable nuclear organisations to: (1) conduct knowledge loss risk assessments to identify specific knowledge loss threats, (2) evaluate the consequences of the loss of
\end{abstract}


critical knowledge and skills, (3) develop action plans to retain this knowledge and (4) use this knowledge to improve the skills and competencies of new and existing workers.

Keywords: attrition; critical knowledge; knowledge loss; risk factor; risk management; workforce.

Reference to this paper should be made as follows: Boyles, J.E., Kirschnick, F., Kosilov, A., Yanev, Y. and Mazour, T. (2009) 'Risk management of knowledge loss in nuclear industry organisations', Int. J. Nuclear Knowledge Management, Vol. 3, No. 2, pp.125-136.

Biographical notes: Ed Boyles received his BS in Biology from the University of North Alabama, USA, in 1970. While working in the field of environmental health with the Public Health Agency of Alabama, he continued his education with graduate work in the area of Biology. In 1979, he received a BS in Civil Engineering from Mississippi State University. He then worked for the Tennessee Valley Authority (TVA) for 26 years as an Engineer and Manager. During that time, he was stationed at the Sequoyah and Watts Bar Nuclear Plants and, beginning in 1991, the corporate office in Chattanooga, Tennessee. In the late 1990s, he was instrumental in developing and implementing TVA's approaches to address the ageing workforce and retain critical knowledge. Since his retirement from TVA in 2005, he has been involved in over 20 IAEA projects (assist visits, workshops, technical meetings, etc.) primarily in the area of knowledge management.

Frank Kirschnick is an Advisor for Knowledge Management and Related Risk Management to several leading European NPP operators and technology providers. His work addresses the key challenges of knowledge management involving content, processes, leadership, culture and IT. His latest contributions focus on the development and implementation of next-generation software tools for risk detection, assessment and mitigation in NPP operations, maintenance and decommissioning. He received a graduate degree in Computer Science from the Technische Universität in Munich and $\mathrm{PhD}$ in Engineering Economic Systems from Stanford University.

Andrei Kosilov obtained his $\mathrm{PhD}$ in Nuclear Engineering at the Moscow Institute for Physics and Engineering (MIPhI), Russia. His particular areas of experience include knowledge management for nuclear industry, nuclear education, human resources development, configuration management, SAT-based training for NPP personnel, management of training document development, NPP instrumentation and control, human-machine interface issues, operator support systems for NPPs, control room systems design, computerisation of operations and maintenance of NPPs and development of web applications. His curriculum vitae contains around 80 publications in national and international journals or presented at international conferences; more than 40 IAEA technical reports have been developed under his supervision. In 2001, he received the American Nuclear Society Training Excellence Award.

Yanko Yanev studied at the University of Sofia, Bulgaria, obtaining an MSc in Nuclear Chemistry and a PhD in Environmental Radiochemistry. For more than 20 years, he developed an academic career as a Professor of Nuclear Chemistry and Head of the Radiochemical Laboratory of the University of Sofia. In 1991, he was appointed Chairman of a government commission which reviewed the nuclear power industry in Bulgaria. The other highlights of his career include being the President of the State Committee on the Use of Atomic 
Energy for Peaceful Purposes from 1991 to 1996 (the Bulgarian Atomic Energy Commission) and Vice Chairman of the IAEA's Board of Governors. He has acted as a Senior Energy Consultant to the Bulgarian-Russian Investment Bank and took up the post of Programme Liaison Officer in the Department of Nuclear Energy at the IAEA in 1998. In 2001, he was appointed Section Head of the International Nuclear Information System (INIS) and has been the agency's cross-cutting Coordinator for Nuclear Knowledge Management since 2002 .

Thomas Mazour received his BS in Mathematics from the Naval Academy (USA) in 1970. After some experience as a US Navy Submarine Officer and while working as a Line Manager and Business Development manager for a technology-oriented consulting company, he continued his education and received his MS and MBA in Industrial Engineering in 1981 from the University of New Haven (USA). Since 1995, he has worked with the IAEA. $\mathrm{He}$ specialises in the training and qualification of NPP personnel, operation and maintenance of nuclear facilities, etc. His curriculum vitae contains around 70 IAEA publications and technical reports that have been developed under his supervision.

\section{Introduction}

It is well established that many NPP operators face a challenge with the loss of experienced workers and the knowledge and skills they possess. Often this knowledge is undocumented and the skills require years of training and experience. This loss may be caused by a variety of factors including: the retirements of long-term employees, internal transfers and promotions, or resignation where employees leave the nuclear industry.

For example, in China, rapid economic development has led to very strong growth in electricity demand, and this situation seems likely to continue. The present plan is to increase capacity by 40000 Megawatts (MW) of safe, reliable and environmentally sound nuclear power by 2020 . This requires strong support in maintaining excellence in safe and reliable operations, minimising the project costs, and maximising the value of nuclear energy assets. The plan will also require the development of the necessary infrastructure and qualified human resources to meet the future needs of the nuclear energy industry.

The China Guangdong Nuclear Power Holdings Company (CGNPC) with its base at Guangdong Province has a vision of building at least one 1000 MW unit per year adding 20 units to its fleet by 2020 to meet Guangdong's electricity demand and fuel diversity programme. This will require that a workforce of 12000 be established to operate these new plants. Before the first plant is commissioned on its new site outside the existing Daya Bay site, the responsibility for on-the-job training and shadow training of these new workers rests solely with Daya Bay Nuclear Power Operations and Management Company (DNMC). The DNMC is an O\&M organisation entrusted by its 2 owners to operate 4 units at the Daya Bay site ( 2 units have been in operations for 11 years and 2 units for 3 years). Current staffing at the site is approximately 1860 employees. DNMC has a relatively young workforce with an average age of 34 years. However, significant 
attrition of experienced staff is anticipated as employees are moved to the new site to support establishment of the operating organisations in preparation for the turn-over from commissioning.

CGNPC and DNMC senior management has initiated anticipatory actions including knowledge loss prevention and retention measures to address the expected experience dilution resulting from retirement and staff turning over to the new plants in the next five years.

In Germany, the political decision to gradually phase out nuclear power has impacted the current and future nuclear workforce. The decision has led to a strong decline of enrolment in academic programmes related to nuclear engineering. In addition, there is a continuing trend of the current NPP workforce to seek opportunities in other regions or industries where there is higher political, public appreciation and expected future stability.

These factors combined with the retirements of long-term employees are creating a shortage qualified NPP workers in anticipation of the national schedule of decommissioning. In particular, this shortage of qualified workers jeopardises the option to prolong NPP operating permits, considering that viable alternatives to nuclear power are not yet in place. The situation in the German nuclear industry is quite different than in China but results in similar Nuclear Knowledge Management (NKM) challenges.

In the USA the general consensus concerning nuclear power appears clear. It is no longer a question of whether new plants will be built but when and where. At the winter 2005 meeting of the American Nuclear Society, Patrick Moore, founder of Greenpeace, and keynote speaker at the conference noted "nuclear power is the only viable source of clean, non-carbon generating and efficient energy that can adequately sustain current and future economic growth without significant impact to the environment". This is a significant shift in the general attitude in the USA concerning the use, advancement and growth of nuclear science and technology in support of energy generation. This positive attitude towards nuclear power is also becoming the norm based on increasing public agreement that, in fact, greenhouse gas production is impacting the global climate. Additionally, events such as the power blackout in the eastern USA, the financial impacts of Hurricane Katrina due to damage to the oil production facilities in the Gulf of Mexico and the high volatility in energy prices underscore the need to actively pursue alternative energy sources.

The anticipated growth in nuclear generating capacity coupled with recent and continuing life extension of existing plants presents an unprecedented demand for a unique workforce resource: the nuclear qualified individual in all of the traditional nuclear power support disciplines. However, in sustaining and advancing the nuclear industry, emphasis and attention is also being placed on both the research and development for next generation reactor types and fuel cycle management options and technologies. These efforts will further draw on the same workforce needed to operate and maintain current plants. Additionally, the construction and licensing of new nuclear energy production facilities will further negatively affect the available workforce. While the challenge internal to the US nuclear industry is great, other industry sectors will be competing for the same college and technical graduates. There are two other complicating factors; the aging US nuclear workforce where literally half the current workers are eligible to retire within the next five years and the lead time required to 
produce an individual capable of safely operating the complex nuclear systems and technologies. In some cases this lead time may exceed the timeframe available to us before substantial retirement of the existing workforce begins.

There are also global dynamics affecting this workforce picture, as well. The USA has for many years been able to bring workers from other countries based on the technical opportunities in the USA. However, as other countries develop a high technology infrastructure (not just in the energy sector) opportunities abound for those that would emigrate to remain in their country. This is a significant impact to the USA's ability to attract technical talent to the nuclear plant operations community. As the new facilities are constructed and other necessary nuclear infrastructure and technology begins to emerge, the ability to attract new talent and the need to have the requisite knowledge resources to train them will impact the ability to bring new facilities and support activities online in a timely enough manner to keep pace with energy demand.

In light of such diverse workforce challenges outlined in these examples above the nuclear industry has taken a more formal approach in recent years to managing its human assets including developing strategies and programmes to capture, retain, and transfer nuclear knowledge and skills.

\section{IAEA guidance on risk management of knowledge loss in nuclear industry organisations}

Several recent major meetings sponsored by the IAEA and others have focused on NKM. These include meetings in November 2003 and June 2004 held in Vienna, a September 2004 International Conference on Knowledge Management - Strategies, Information Management and Human Resource Development, Saclay, France, May 2007 International Conference on Knowledge Management in Nuclear Facilities, Vienna, Austria and the Meeting of Senior Officials on Nuclear Knowledge Management - Cooperation for Development in May 2008.

In addition, recent assist visits (Krsko, Paks, Kozloduy, Ignalina, Darlington, Bruce and Zaporozhe NPPs) by WANO and IAEA have addressed NPP needs to develop effective Knowledge Management (KM) strategies and programmes. During these assist visits NPP management has identified the needs for specific guidance and tools to help in the development and implementation of NKM programmes. NPPs often need to know how to begin the development of effective programmes. Assist visits and technical meetings are helpful but may address NKM from a broad perspective. To support Member States activities on NKM the IAEA published a report on Risk Management of Knowledge Loss in Nuclear Industry Organizations (STI/PUB/1248) which is focused on providing specific processes and tools to conduct risk assessments to determine the potential for knowledge loss to the NPP and identify steps to manage this loss. The processes and tools can be adapted or modified for use by a wide variety of organisations.

\section{Knowledge management terminology}

KM can be a broad and complex area of study subject to wide interpretation. For purposes of this paper the following definitions are used: 
- $K M$ : The integrated, systematic approach to identifying, acquiring, transforming, developing, disseminating, using, sharing, and preserving knowledge, relevant to achieving specified objectives. KM helps an organisation to gain insight and understanding from its own experience. Specific activities in KM help the organisation to better acquire, store and utilise knowledge.

- Attrition: A decrease in the number of employees in an organisation due to retirements, other termination, or transfers to other organisations.

- Critical knowledge: The knowledge established in the context of a particular position that is deemed imperative for incumbents of said position to possess before being allowed to perform associated duties and tasks independently.

- Human assets: The knowledge, skills and competencies of the people in an organisation.

- Institutional knowledge: The collective knowledge of all the employees working in an organisation or institution.

- Knowledge: The acquiring, understanding and interpreting of information. Knowledge is often used to refer to a body of facts and principles accumulated by humankind over the course of time. Explicit knowledge is knowledge that can be easily expressed in documents. Implicit knowledge and tacit knowledge represent knowledge or know-how that people carry in their heads. Explicit knowledge is contained in documents, drawings, calculations, designs, databases, procedures and manuals. Implicit knowledge and tacit knowledge are held in a person's mind and have typically not been captured or transferred in any form (if they had, they would then become explicit knowledge). Compared with explicit knowledge, such knowledge is more difficult to articulate or write down and so it tends to be shared between people through discussion, stories and personal interactions. It includes skills, experiences, insight, intuition and judgement.

\section{Strategic approach to managing workforce issues}

Many NPPs recognise that an integrated and strategic approach is most effective in addressing the broad array of workforce issues, which many organisations face. While this paper focuses on managing the risk associated with potential loss of nuclear knowledge, the interactions between KM and other people-centred programmes should be considered. These programmes may include the following:

- workforce planning

- recruiting initiatives

- training programmes

- succession planning and leadership development

- KM. 
For example, if a potential for knowledge loss is identified involving a plant expert on auxiliary power, solutions may involve a recruiting initiative and/or developing a formal training module. The pending retirement of an experienced component engineer may require recruiting, training, and succession planning. There are numerous other examples where an integrated, strategic approach must be taken to ensure the overall effectiveness of these related programmes.

\section{Risk assessment processes and tools}

The following processes and tools can be used by NPPs to identify and mitigate knowledge loss threats. Management can adapt or modify these processes and tools to meet the specific needs of their organisation.

\subsection{Attrition related knowledge loss risk assessment}

Attrition-related knowledge loss threats can be identified, prioritised and addressed using the following process to determine a 'Total Risk Factor' for each employee in the organisation. This Total Risk Factor is based on a projected attrition date which could be retirement, transfer, or other attrition (Attrition Risk Factor) and criticality of knowledge and skill (Position Risk Factor). Figure 1 provides a flow diagram of the critical Knowledge Retention (KR) process.

Figure 1 Critical knowledge retention flow chart

\begin{tabular}{|ccc|}
\hline Step 1 & Step 2 & Step 3 \\
Conduct & Determine and & Monitor and Evaluate \\
Risk Assessment & Implement Plan & \\
\hline
\end{tabular}

\section{Step 1: Conduct a knowledge loss risk assessment}

The knowledge loss risk assessment is designed to identify positions/people where the potential for knowledge loss is greatest and most imminent.

The Attrition Risk Factor is based on the expected retirement or other attrition date. The date can be provided by the employee or calculated based on age and tenure data. Table 1 lists the criteria used to assign an Attrition Risk Factor.

Table 1 Attrition risk factor criteria

\begin{tabular}{ll}
\hline Retirement factor & Criteria \\
\hline 5 & Projected attrition date within two years \\
4 & Projected attrition date within three years \\
3 & Projected attrition date within four years \\
2 & Projected attrition date within five years \\
1 & Projected attrition date within (or greater than) six years \\
\hline
\end{tabular}


The Position Risk Factor is initially assigned by the department level manager using criteria listed in Table 2.

Table 2 Position risk factor criteria

\begin{tabular}{ll}
\hline $\begin{array}{l}\text { Position } \\
\text { risk factor }\end{array}$ & Criteria \\
\hline 5 & $\begin{array}{l}\text { Critical and unique knowledge or skills. Mission-critical knowledge/skills with the } \\
\text { potential for significant reliability or safety impacts. Organisation or site-specific } \\
\text { knowledge. Knowledge undocumented. Requires extensive training and on the job } \\
\text { experience to reach full competency. No ready replacements available. }\end{array}$ \\
& $\begin{array}{l}\text { Critical knowledge and skills. Mission-critical knowledge/skills. Some limited } \\
\text { duplication exists at other plants/sites and/or some documentation exists. Requires } \\
\text { significant training and on the job experience to reach full competency. }\end{array}$ \\
& $\begin{array}{l}\text { Important, systematised knowledge and skills. Documentation exists and/or other } \\
\text { personnel on-site possess the knowledge/skills. Recruits generally available with } \\
\text { pipeline training programmes in place. }\end{array}$ \\
& $\begin{array}{l}\text { Procedural or non-mission critical knowledge and skills. Clear, up-to-date } \\
\text { procedures exist. Training programmes are current and effective and can be } \\
\text { completed in a timely manner to reach full competency. } \\
\text { Common knowledge and skills. External hires possessing the knowledge/skills are } \\
\text { readily available and require little additional training. }\end{array}$ \\
&
\end{tabular}

The Position Risk Factor criteria are based on the unique/critical knowledge and skills possessed by the employee and an estimate of the difficulty or level of effort required to refill the position. In assigning the factor the manager should consider each employee's responsibilities and background, formal and informal roles, collateral duties, reoccurring assignments (e.g., outage-related duties, problem-solving or trouble-shooting assignments), and other factors suggesting that the employee may have unique/critical knowledge and skills. Department managers may want to consult other work group members, key plant customers, or interested parties when determining ratings.

The Total Risk Factor of an employee is determined base on the guidelines provided in Table 3.

Table 3 Total risk factor

\begin{tabular}{|c|c|}
\hline Total risk factor & Priority \\
\hline $20-25$ & $\begin{array}{l}\text { High priority - Immediate action needed. Specific replacement action } \\
\text { plans with due dates will be developed to include: Knowledge retention } \\
\text { plan, knowledge management assessment, specific training required, } \\
\text { on-the-job training/shadowing with incumbents. }\end{array}$ \\
\hline $16-19$ & $\begin{array}{l}\text { Priority - Staffing plans should be established to address method and } \\
\text { timing of replacement, recruitment efforts, training, shadowing with } \\
\text { current incumbent. }\end{array}$ \\
\hline $10-15$ & $\begin{array}{l}\text { High importance - Consider how the position will be filled/work will be } \\
\text { accomplished. College recruiting, training programmes, process } \\
\text { improvements, reinvestment. }\end{array}$ \\
\hline $1-9$ & $\begin{array}{l}\text { Important - Recognise the functions of the positions and determine the } \\
\text { replacement need. }\end{array}$ \\
\hline
\end{tabular}


The Total Risk Factor provides an overall assessment of attrition-related risk for knowledge loss. The Total Risk Factor is computed by multiplying the Attrition Risk Factor by the Position Risk Factor (see Table 4).

Table 4 Example of computing of total risk factor

\begin{tabular}{ll}
\hline Overall assessment & Risk factor \\
\hline Projected attrition within 1 year & Attrition factor $=5$ \\
Critical/Unique knowledge/skills & Position risk factor $=5$ \\
& Total Risk Factor $=5 \times 5=25$ \\
\hline
\end{tabular}

Each NPPs management team should collectively review the results of the risk assessment. Experience has shown that a critical review of the Position Risk Factor assigned by the department manager is important in ensuring accurate ratings. Often there is a tendency to rate high performing employees as having unique and critical knowledge and skills. A high level of performance is not the basis for a high Position Risk Factor (5 rating) and such ratings should be changed. After completing the collective review, the management team identifies where a KR plan is needed and assigns responsibility for plan development (typically, the employee's supervisor or manager).

\section{Step 2: Determine the approach to capture critical knowledge}

Once the risk assessment is complete, the next step is to address potential knowledge loss for each high priority (20-25 Total Risk Factor) employee. In many cases this will involve an interview with the employee ('elicitation' process) utilising a trained elicitor. The knowledge and skill in question may be of many different types - task and equipment-related knowledge and skill; facts or information about specific people, vendors, projects, and locations; and unique pattern recognition knowledge and problem-solving skills. The interviews employ questionnaires designed to assist the elicitor and employee in identifying the specific areas where critical/unique knowledge may exist. Based on the results of the interviews KR plans are developed and implemented. The process for determining and implementing the most appropriate method(s) for addressing this potential loss involves:

- $\quad$ inventorying the specific knowledge and skills of the identified employee

- $\quad$ assessing the importance to the organisation - criticality

- $\quad$ assessing the consequences of loss (e.g., operational, financial, etc.)

- reviewing options to mitigate (e.g., codification, alternate resources, reengineering)

- developing KR plans as needed

- implementing KR plans

- coordinating and reviewing KR plans. 
Note: The first priority is to identify, capture and retain critical knowledge held by employees nearing retirement. However, it is also important to develop and implement a KR plan for any employee with a Position Risk Factor of five. These employees may be promoted, transferred, or leave the organisation for other reasons thus resulting in the loss of critical knowledge.

\section{Step 3: Monitor and evaluate}

Periodic reviews should be conducted to monitor the status of implementation of the KR process. Specifically this step should:

Step 1 Review previous KR plans and progress

Step 2 Identify any positions/incumbents for reassessment or KR plan development

Step 3 Identify related emerging issues or points of coordination

Step 4 Review KR metrics, including:

- future attrition projections

- number of high priority positions

- number of positions targeted for KR plan development

- status of KR plans (complete, on-track, etc.)

- knowledge-related organisation metrics (human performance, safety, etc.)

- consider the impact of other activities on the risk assessment (e.g., emerging work).

Step 5 Evaluate the success of KR plans in accomplishing stated goals.

\subsection{Employee self-assessment - knowledge retention process}

Often the expert employee who has undocumented knowledge is critical to day-to-day operations of the NPP and therefore their time is valuable and limited. Processes such as the one outlined above are effective, but may require significant resources and time. The 'Employee Self-Assessment Knowledge Retention Process' can be much less time consuming when utilised by NPPs to allow for self-assessments to identify specific at risk knowledge. This approach can be used to address potential knowledge loss when employees are terminating, transferring, being promoted, etc. The process can facilitate the gathering of additional information pertinent to the individual's knowledge, skills and duties to support the continued safe and efficient operation of the NPP.

The self-assessment consists of two steps - the Employee Self-Assessment and the Employee Task Assessment. The Employee Self-Assessment is geared to provide general information from the employee of their current job tasks as well as information regarding meetings they attend, emergency position they hold, etc. The Employee Task Assessment provides more specific information about 1-5 major tasks performed by the employee. These major tasks may include activities they perform as part of their everyday job or may be collateral duties such as outage assignments. 
The critical knowledge held can either be apparent where the individual is recognised as 'the' expert in a task or area, or it may be 'deep-seated', where critical steps are so ingrained in the individual that they may or may not recognise it as critical. This method of self-elicitation may need to be followed up with a more detailed review of the employee's information to ensure that critical knowledge is not lost.

Once the employee has completed both the Employee Self-Assessment and the Employee Task Assessment, department managers and supervisors should review the tasks performed by the individual and make a decision as to whether additional assessments are needed. The completed self-assessment is retained by the manager and is used to address challenges created by the pending personnel changes as well as potential knowledge loss.

\subsection{Institutional knowledge loss risk management}

Institutional knowledge is defined as the collective knowledge of all the employees working in an organisation or institution. The necessity to maintain organisational competency for NPPs has been widely recognised by member states given the nature of the business (high hazard low risk) and the 100 years or more life cycle. They recognise the importance in continuing the safe and efficient operation of existing NPPs, continued support for research and development and educational institutions, as well as the need to support the expansion of nuclear power.

The three examples (covered in the Introduction) of China, Germany and the USA, demonstrate that different situations or life cycle stages exist that may contribute to the potential loss of knowledge and skill in the nuclear industry. However, all three share the common challenge of managing nuclear knowledge to maintain and enhance institutional knowledge.

As with specific knowledge loss threats organisations should periodically assess the risk of institutional knowledge loss. This assessment should consider both internal (e.g., loss of experienced workers) and external (business and political) factors. Other considerations include:

- Current work load: Provide an assessment of the current workload in the organisation or department. Consider current work backlogs, amount of overtime (paid and unpaid), and levels of stress in workforce. Identify core and non-core functions performed and the impact of not performing. Identify options to address any potential knowledge loss issues (e.g., process improvements, reorganisation, and elimination of non-core activities).

- Future work load: Evaluate future staffing needs based on an assessment of future workload (expanding capacity, decommissioning, restart, major modifications, etc.). Consider lag time in recruiting, training, and time until full competency.

- Areas where critical knowledge and skills are at risk: Based on current information identify any areas that exist where critical knowledge and skills are at risk to the organisation. These areas may be general areas (e.g., System Engineering) or specific to individual experts (Turbine Specialist). List each area or individual and include 'what' is at risk. Include the cause of the threat (e.g., retirement, transfer, other). 
- Risk and impact: Based on workload assessments what risk exists and what will the impact be to organisational performance. Consider what work can go forward and what will be deferred. Where possible, quantify the impact on safety, performance, and cost.

- Current programmes or proposed initiatives that support KM: Recognise existing programmes and processes and their contribution to the retention and enhancement of institutional knowledge. These may include: corrective acting programmes, configuration control process, or change management tools. Be as specific as possible and identify gaps where programmes or processes need to be improved.

Based on the assessment results, develop a strategic plan to address institutional knowledge loss.

\section{Conclusions}

The KM tools and processes presented in this paper are intended for use by NPP operators to assist in managing the risk of knowledge loss caused by the loss of experienced personnel. The guidance addresses mainly the risk of knowledge loss with individual workers but can be applied to the institutional knowledge of an organisation or institution. The processes and tools are easily adaptable and can be modified to meet the needs of a wide range of organisations (e.g., chemical, aerospace, governmental, etc.).

The Attrition Related Knowledge Loss Risk Assessment process has been successfully utilised by the Tennessee Valley Authority's nuclear organisation. This includes all three NPPs (Browns Ferry, Sequoyah and Watts Bar) and the corporate office in Chattanooga Tennessee. In addition, the process has been applied in a modified form by a European NPP operator, and benchmarked by numerous other organisations and agencies (e.g., Entergy, Bruce Power, Ontario Power Generation, Nuclear Regulatory Commission and INPO). As with most management processes, implementation is often the weak link, necessitating periodic monitoring and follow up.

It is important to restate that these tools and processes are not stand alone initiatives but should be a part of an overall KM system. KM is not intended to replace existing systems, processes or programmes but rather to increase the overall benefit by providing an integrated approach to manage knowledge loss. 